\title{
End-of-life services for older people in residential care homes in Hong Kong
}

\author{
James KH Luk *
}

This article was published on 4 Aug 2017 at www.hkmj.org.

\section{A B S T R A C T}

Good end-of-life care is needed for older people living in residential care homes with advanced irreversible chronic medical illnesses and cancers. At present, the usual practice of residential care homes is to send older residents to acute care hospitals when they are unwell, and some residents will die in hospital. Dying in hospital without choice for older people may not be in alignment with the principle of 'good death' There are many barriers for older people to die in the place of their choice, particularly in a residential care home. In the community, to enhance end-of-life care for elderly people living in residential care homes, pilot end-of-life programmes have been organised by community geriatric assessment teams. In 2015, the Hong Kong Hospital Authority started the 'Enhance community geriatric assessment team support to end-of-life patients in residential care homes for the elderly' programme in four clusters. In the hospital setting, an end-of-life clinical plan and end-of-life ward in geriatric step-down hospitals may improve the quality of death of elderly people. In September 2015, the Hospital Authority guideline on lifesustaining treatment for terminally ill people was updated. Among other key end-of-life issues, careful (comfort) hand feeding was first mentioned in the guideline. The possible establishment of enduring powers of attorney for health care decision-making and enhancement of careful (comfort) hand feeding are new developments in the coming years.

\section{Hong Kong Med J 2018;24:63-7}

DOI: $10.12809 / \mathrm{hkmj} 166807$

JKH Luk *, FHKCP, FHKAM (Medicine)

Department of Medicine and Geriatrics, Fung Yiu King Hospital, Pokfulam, Hong Kong

* Corresponding author: lukkh@ha.org.hk

\section{Introduction}

The population of Hong Kong is ageing rapidly. ${ }^{1}$ Approximately $8.5 \%$ of those aged 65 years and above live in a residential care home for the elderly (RCHE) in Hong Kong. ${ }^{2}$ Older RCHE residents are characterised by multiple co-morbidities, with many advanced irreversible chronic medical illnesses (advanced dementia, chronic lung or heart diseases, end-stage renal failure, and Parkinson's disease, to name but a few). They may also have cancers that require palliative rather than curative treatment. Many have poor mobility, high dependency, and poor cognitive function. ${ }^{3}$ It is increasingly realised that, similar to cancer patients, good end-of-life (EOL) care is important in the management of patients with irreversible chronic illnesses. ${ }^{4}$ Indeed, high mortality has been reported in RCHE residents with advanced dementia, with a 1-year mortality rate of $34 \%{ }^{5}$ As the EOL stage approaches, patients with advanced irreversible chronic medical illnesses may experience distressing symptoms similar to patients dying of more commonly recognised terminal conditions..$^{6-8}$ Therefore, it is advocated that EOL care should be provided for this vulnerable group. ${ }^{9}$

Previous literature has laid down the concept of a 'good death', which includes being able to know when death is approaching; retaining control of what happens; having dignity, privacy, and pain and symptom control; having choice and control over where death occurs (at home or elsewhere), access to information and expertise, access to spiritual or emotional support, access to hospice care in any location, and control over who is present; having the ability to issue advance directives; having time to say goodbye; and leaving when it is time to go instead of having life prolonged pointlessly. ${ }^{10}$ Unfortunately, most, if not all, elderly patients living in RCHEs with advanced irreversible chronic medical illnesses die in public hospitals. ${ }^{11}$ Acute medical and surgical wards in public hospitals are intended for acute curative management of ill patients. They are not generally well-designed for dying with dignity and privacy. Elderly patients will die in an unfamiliar environment with restricted visiting hours. Ward staff are busy and most have not been trained to provide counselling and spiritual care to dying patients and family members. A single room with privacy for a dying patient is unavailable in most public hospitals, except in some palliative care units. The dying experience for RCHE residents with advanced irreversible chronic medical illnesses is still far from a 'good death' in Hong Kong. ${ }^{12}$

\section{Can we have an alternative in the place of dying?}

'Dying in place' is one of the elements of a good 


\section{香港老年人在安老院的晚期護理服務}

\section{陸嘉熙}

安老院舍中罹患慢性疾病或末期癌症的老年人需要獲得良好的晚期護 理服務。目前, 安老院的慣常做法是將有病的老年人送到急診醫院, 有些病人會在醫院內死亡。沒有選擇而在醫院死去的老年人可能不符 合「好死」的原則。老年人面對選擇死亡的地方會遇到許多障礙, 尤 其是經已入住安老院舍內的院友。為加強安老院舍內的護理服務, 社 區老人評估小組進行了試點晚期護理服務。醫院管理局於 2015 年在四 個聯網內開展了社區老人評估小組, 負責安老院舍的晚期醫護服務。 在醫院內實施臨終照顧計劃以及臨終病房可能會提高老年人臨終前的 生活質素。醫院管理局於 2015 年9月對維持末期病人生命治療的指引 作出更新。在各項晚期護理的關鍵問題上, 該指引首先提及的是 $\Gamma$ 人 手小心餵食」。未來幾年的新發展可能是按健康護理事宜作出決定的 《持久授權書》以及加強「人手小心餵食」兩方面。 death. ${ }^{13}$ Dying in place usually means dying at home or in an RCHE, as opposed to a hospital. ${ }^{14}$ If an elderly person dies at home, there is no need to inform the Coroner. A registered practitioner can fill in a Medical Certificate of the Cause of Death (Form 18) of the Births and Deaths Registration Ordinance (Chapter 174). The form is available from the offices of the Registrar of Births and Deaths. ${ }^{15}$ The practitioner must have attended the patient within 14 days immediately prior to the patient's death. Using Form 18, the deceased's family has to register a death within 24 hours at the Births and Deaths General Register Office. After death registration, a Certificate of Registration of Death (Form 12) will be issued. According to Section 16 of the Births and Deaths Registration Ordinance, no person shall remove a dead body, unless they have obtained either Form 12 or, in urgent cases, a permit from the nearest police station. ${ }^{16}$ The problems for dying in place in Hong Kong include social taboo, lack of death education, fear of depreciation of property value if a person died at home, and inadequate medical support to take care of dying persons at home. ${ }^{17,18}$

For an RCHE, the Coroner Ordinance (Section 4, Coroner Ordinance, CAP 504) demands all deaths in RCHEs (except nursing homes) be reported to the Coroner. ${ }^{19}$ Because of the above ordinance, RCHEs are disinclined to allow an older resident to die in their premises. When they see a patient's health is deteriorating, they will call an ambulance to take the patient to the accident and emergency department (AED). Moreover, RCHE staff are largely untrained in managing EOL patients. Environmentally, RCHEs are largely overcrowded, with no extra room for a resident to pass their last moments in privacy. Geriatric and palliative care specialists available to RCHEs are also insufficient. The lack of a family practice model whereby doctors would visit patients at home or the RCHE to provide EOL care is another obstacle.

\section{New developments in end-of-life care at residential care homes for the elderly}

The wishes of older people in RCHEs has been the subject of research recently. One study showed that $28.8 \%$ of the older residents wished to die in the RCHE as an alternative to a hospital. ${ }^{20}$ Another local study showed that $35 \%$ of older people would prefer dying in their RCHEs. ${ }^{21} \mathrm{~A}$ pioneer programme in the Haven of Hope Nursing Home has achieved favourable results, with nearly $30 \%$ of all deaths occurring in the nursing home. ${ }^{22}$

There have been encouraging developments in EOL care for older people in RCHEs in the past 10 years. A new model of EOL care has been implemented in the New Territories East Cluster in Hong Kong aiming at promoting quality EOL care for $\mathrm{RCHE}$ residents, through the establishment of an advance care plan (ACP) and introduction of a new care pathway. ${ }^{23}$ The pathway bypasses the emergency and acute medical wards by direct clinical admission to an extended-care facility. A study on this programme shows that nearly $40 \%$ of EOL patients could be managed entirely in an extended-care setting without compromising the quality of care and survival. ${ }^{23}$

In September 2009, the Hong Kong West Community Geriatric Assessment Team (HKW CGAT), which is based at the Tung Wah Group of Hospitals Fung Yiu King Hospital (FYKH), piloted the EOL programme for RCHE in cooperation with two care and attention homes. ${ }^{24}$ The programme aimed at providing EOL care for older RCHE residents with advanced irreversible chronic medical illnesses and cancers, ensuring the elderly people were able to have a comfortable and dignified period in the RCHE before they died. The Gold Standards Framework for the three illness trajectories was used to identify suitable candidates to join the EOL programme. ${ }^{25}$ In the programme, there were weekly EOL clinics and family conferences. An ACP and Do-Not-Attempt Cardiopulmonary Resuscitation (DNACPR) [non-hospitalised] option would be established. If patients were cognitively intact, an advance directive would also be created based on the wishes of the older residents. The patients/family members could select one of the two pathways, specifically the Hospital Pathway and AED Pathway. In the Hospital Pathway, an elderly person would be clinically admitted to a geriatric step-down hospital (instead of an acute care hospital) that was suitable for EOL care via an expedited route. In the AED Pathway, an elderly person would stay in the RCHE for as long as possible with support from the RCHE 
staff and the EOL team of HKW CGAT. At the last moment (when the patient becomes unconscious, his/her breathing becomes shallow, and/or blood pressure starts to drop), he/she would be transferred to the AED by ambulance. Resuscitation would still be carried out by the ambulance staff, as the Fire Services Ordinance in Hong Kong stipulates that resuscitation has to be carried out for their patients. When the patient reaches the AED, resuscitation would not be offered. Instead, a single room would be offered in the AED, allowing family members to stay with the dying patient. The AED doctors would help to certify death when the patient passed away, whereas the death certificate would be signed by the HKW CGAT doctors who had seen the patient within the previous 2 weeks.

An audit of the programme was performed to study the RCHE residents who had joined the piloted EOL programme for RCHE and passed away in the AED between September 2009 and August 2014. ${ }^{26}$ Twenty-two patients joined the programme with AED Pathway during the audit period. Nine (41\%) patients finally died in the AED. When they arrived at the AED, all were not resuscitated according to the DNACPR (non-hospitalised) order and were allocated a single room for the family members to say goodbye. In the last 180 days before death, they had an average (per person) of 2.67 AED attendances (including the death episode in the AED), 1.67 medical admissions, and 16 medical bed-days. These figures were lower than those reported by the Hospital Authority in 2012 (2.98 AED attendances, 2.56 medical admissions, 26 medical bed-days) for local RCHE residents during the last 180 days of life. ${ }^{26}$ It seems that the AED Pathway was logistically feasible and potentially could reduce AED and hospital service utilisation. The programme is also a good model of medico-social collaboration in taking care of EOL patients.

In October 2015, a programme called 'Enhance community geriatric assessment team support to end-of-life patients in residential care homes for the elderly' was implemented by the Hospital Authority in Hong Kong. It was first started in Hong Kong West, Hong Kong East, New Territories West, and New Territories East clusters in 2015. In the programme, the CGAT service is enhanced, with a link-nurse as a case manager for older people in RCHEs approaching the EOL stage. The CGAT also collaborates with palliative care specialists to implement this programme. In the Hong Kong West Cluster, the CGAT collaborates with the Palliative Medical Unit of the Grantham Hospital. The Unit provides training to RCHE and CGAT staff, holds regular case conferences with the HKW CGAT, and assists in complex case management. To avoid duplication of service provision, RCHE patients who have been seen by the palliative care team are not recruited into the CGAT EOL programme. An ACP will be deliberated with patients and family members, and documented in a standard ACP form. Orders of DNACPR (non-hospitalised) are made if agreed by a patient or family members. An advance directive may also be signed if the patient is mentally sound and wishes to do so. The RCHE staff bring the ACP, DNACPR (non-hospitalised) records, and advance directive document (if available) whenever the older residents attend the AED or are admitted to hospital. An ACP without an advance directive is not legally binding. The health care team, if possible, will usually act in accordance with the wishes of the patients and family members as laid down in the ACP. The final treatment decision will be based on the assessment and judgement of the health care team. An advance directive is a legally binding order and has to be strictly adhered to by the health care team. The plan of the Hospital Authority is to expand the enhanced CGAT support to EOL patients in RCHE service to all clusters in the near future.

\section{End-of-life care for older patients in the hospital setting}

In view of the rising number of older patients with advanced and irreversible chronic medical illnesses dying in hospitals, FYKH-a geriatric step-down hospital-established the End-of-Life Clinical Plan for Inpatients (EOL-CPi) in 2012. At the time of writing, the EOL-CPi has been used for nearly 400 patients. A recently published study shows that a tailor-made clinical plan could be useful to guide the team in fostering dignified death in dying patients in a geriatric step-down hospital. ${ }^{27}$ Patients and relatives are satisfied with the programme as a whole. In August 2015, an EOL ward with eight beds was established in FYKH. A preliminary study of 149 patients who died in the EOL ward shows that it can enhance dignified death by providing a peaceful environment so that family members are able to stay with the patient for as long as possible before they die (unpublished data).

\section{Feeding problems in end-of-life care}

Poor feeding or swallowing difficulties may occur at the end stage of cancers. Similarly, many irreversible chronic diseases are associated with eating problems at the EOL stage. For instance, dementia, at the end stage, is commonly associated with feeding problems. When eating difficulties arise, unless there is a valid advance directive refusing enteral feeding, tube feeding is often started in Hong Kong. Tube feeding has shortcomings and complications. ${ }^{28-30}$ As yet, no benefits of survival or nutrition, and aspiration reduction have been demonstrated. Residents in RCHE with feeding tubes are 
frequently transferred to the AED to manage tube complications such as blockage and dislodgement. ${ }^{31}$ Different societies throughout the world, including the American Geriatrics Society and the Australian and New Zealand Society for Geriatric Medicine, have recommended against the use of tube feeding in advanced dementia, at least as the only option..$^{32,33}$ Careful (or comfort) hand feeding (CHF) should be offered as it is at least as good as tube feeding for the outcomes of death, aspiration pneumonia, and comfort. ${ }^{34,35}$ In September 2015, the Hospital Authority guideline on life-sustaining treatment in the terminally ill was updated. ${ }^{36}$ Among other key EOL issues, it provides a clear and locally relevant picture of $\mathrm{CHF}$ from the ethical perspective. ${ }^{36}$ In some geriatric step-down hospitals such as $\mathrm{FYKH}, \mathrm{CHF}$ is already incorporated as one of the management strategies for EOL patients. There are many practical difficulties, however, if $\mathrm{CHF}$ is used in EOL care for older patients with feeding difficulties in Hong Kong. Training of health care teams, better nursing staff-to-patient ratio, and elderly-friendly ward design are all essential elements for more elderly patients to be offered CHF. Training of RCHE staff and staff-resident ratio will be vital factors to determine whether CHF can be smoothly practised in the community of Hong Kong. Without a wellprepared EOL plan, patients receiving CHF will be given enteral tubes. The Social Welfare Department can play a role in encouraging RCHEs in practising EOL care and CHF. More training in EOL issues should be given to primary doctors who look after older people with advanced and irreversible chronic medical illnesses. ${ }^{37}$

\section{What's next?}

Many new developments in EOL care have been seen in the past 10 years in Hong Kong. It is encouraging to see that the Hong Kong SAR Government has begun to look into EOL care for older people in the past few years. Many other organisations, including the Hong Kong Jockey Club, have funded innovative programmes and research projects in EOL themes. Notwithstanding, in the 2015 Quality of Death Index by The Economist, Hong Kong ranks 22nd in the world (Singapore ranks 12th and Taiwan sixth). ${ }^{38}$ This shows that Hong Kong still has a lot to do to catch up with other Asian neighbours. Further development and expansion of an EOL programme for older people with advanced and irreversible chronic medical illnesses in Hong Kong, in particular for those living in RCHEs, is needed. The Hospital Authority has to work with the Fire Services Department to establish guidelines for avoiding resuscitation among terminally ill patients who have opted for no resuscitation in an advance directive or in another form of ACP. At the time of writing this article, the Hong Kong Special Administrative
Region Government is exploring the realisation of enduring power of attorney for health care decisionmaking, allowing mentally incapacitated older people to express their wishes through a chosen advocate..$^{39}$ In academia, more studies of EOL issues in the Hong Kong Chinese population are needed. For instance, although the notion of 'good death' has been described in western societies, the concept of 'good death' among Chinese population, especially those who are frail or confused with multiple comorbidities including advanced dementia, has not been fully delineated. Accurate prediction of life expectancy is often difficult in older non-cancer patients, including those with advanced dementia and chronic irreversible medical illnesses. Future studies are needed to establish a validated tool applicable to local Chinese older patients in predicting mortality.

\section{Declaration}

The author has disclosed no conflicts of interest.

\section{References}

1. Hong Kong population projections 2012-2014. Hong Kong: Census and Statistics Department, the Government of the Hong Kong Special Administrative Region.

2. Luk JK, Chiu PK, Chu LW. Factors affecting institutionalization in older Hong Kong Chinese patients after recovery from acute medical illnesses. Arch Gerontol Geriatr 2009;49:e110-4.

3. Luk JK, Chan FH, Pau MM, Yu C. Outreach geriatrics service to private old age homes in Hong Kong West Cluster. J Hong Kong Geriatr Soc 2002;11:5-11.

4. Lo RS, Woo J. Palliative care in the elderly. J Hong Kong Geriatr Soc 2000;10:16-24.

5. Luk JK, Chan WK, Ng WC, et al. Mortality and health services utilisation among older people with advanced cognitive impairment living in residential care homes. Hong Kong Med J 2013;19:518-24.

6. Gibbs LM, Addington-Hall J, Gibbs JS. Dying from heart failure: lessons from palliative care. Many patients would benefit from palliative care at the end of their lives. BMJ 1998;317:961-2.

7. Caird FI. The importance of psychological symptoms in Parkinson's disease. Age ageing 1999;28:335-6.

8. Mitchell SL, Kiely DK, Hamel MB, Park PS, Morris JN, Fries BE. Estimating prognosis for nursing home residents with advanced dementia. JAMA 2004;291:2734-40.

9. Marsh GW, Prochoda KP, Pritchett E, Vojir CP. Predicting hospice appropriateness for patients with dementia of the Alzheimer's type. Appl Nurs Res 2000;13:187-96.

10. Smith R. A good death. An important aim for health services and for us all. BMJ 2000;320:129-30.

11. Luk JK, Kwok T, Woo J. Geriatric screening in acute care wards-a novel method of providing care to elderly patients. Hong Kong Med J 1999;5:34-8.

12. Chan WC, Tse HS, Chan TH. What is good death: bridging the gap between research and intervention. Death, dying and bereavement-a Hong Kong experience. Chapter 9. Hong Kong: Hong Kong University Press; 2006.

13. Luk JK, Liu A, Ng WC, Lui B, Beh P, Chan FH. End-of-life care: towards a more dignified dying process in residential 
care homes for the elderly. Hong Kong Med J 2010;16:2356.

14. Chan KS. Peaceful death in nursing home-a family perspective. Hong Kong Society of Palliative Medicine Newsletter 2006;(3):3.

15. Registration of a death. Available from: http://www.gov. hk/en/residents/immigration/bdmreg/death/deathreg/ naturalcause.htm. Accessed 18 Mar 2017.

16. Application for a permit for removal of dead body from Hong Kong. Available from: http://www.immd.gov.hk/eng/ services/birth-death/Apply_for_a_permit_to_remove_a dead_body_from_Hong_Kong.html. Accessed 18 Mar 2017.

17. Luk JK, Liu A, Ng WC, Beh P, Chan FH. End-of-life care in Hong Kong. Asian J Gerontol Geriatr 2011;6:103-6.

18. Lam PT, Madocks I. Dying in place-palliative care in nursing home-an Australian perspective and its relevance to Hong Kong. Hong Kong J Gerontology 1998;12:49-53.

19. Hong Kong Ordinances: CAP 504 Coroners Ordinance. Available from: http://www.hklii.org/hk/legis/en/ord/504/. Accessed 18 Mar 2017.

20. Luk JK, Chu LW, Chan FH, Sham MM, Szeto Y, Law PK. A study of the knowledge and preferences in Chinese elderly concerning advance directive. Proceedings of the Hospital Authority Convention 2007; 2007 May 7-8; Hong Kong.

21. Chu LW, Luk JK, Hui E, et al. Advance directive and endof-life care preferences among Chinese nursing home residents in Hong Kong. J Am Med Dir Assoc 2011;12:14352.

22. Chu WW, Leung AC, Lam C, Chan KS, Chui YT. An evaluation of a shared care program in end-of-life care service in a sub-vented nursing home in Hong Kong. Proceedings of the Hospital Authority Convention 2004; 2004 May 8-11; Hong Kong.

23. Hui E, Ma HM, Tang WH, et al. A new model for end-of-life care in nursing homes. J Am Med Dir Assoc 2014;15:287-9.

24. Ho AH, Luk JK, Chan FH, et al. Dignified palliative longterm care: an interpretive systemic framework of end-oflife integrated care pathway for terminally ill Chinese older adults. Am J Hosp Palliat Care 2016;33:439-47.

25. The National Gold Standards Framework Centre in End of Life Care. Available from: http://www. goldstandardsframework.org.uk. Accessed 18 Mar 2017.

26. Luk JK, Chan TC, Chan WK, Ng WC, Mok WW, Chan $\mathrm{FH}$. End of life program in residential care homes reduces unnecessary hospital admissions and fosters 'good death' in last phase of life. Proceedings of the Hospital Authority
Convention 2015; 2015 May 18-19; Hong Kong.

27. Luk JK, Chan TC, Mok WW, Wong EK, Chan FH. End-oflife clinical plan in a geriatric step-down hospital. Asian J Gerontol Geriatr 2016;11:42-7.

28. Luk JK, Chan DK. Preventing aspiration pneumonia in older people: do we have the 'know-how'? Hong Kong Med J 2014;20:421-7.

29. Kuo S, Rhodes RL, Mitchell SL, Mor V, Teno JM. Natural history of feeding-tube use in nursing home residents with advanced dementia. J Am Med Dir Assoc 2009;10:264-70.

30. Teno JM, Mitchell SL, Kuo SK, et al. Decision-making and outcomes of feeding tube insertion: a five-state study. J Am Geriatr Soc 2011;59:881-6.

31. Odom SR, Barone JE, Docimo S, Bull SM, Jorgensson D. Emergency department visits by demented patients with malfunctioning feeding tubes. Surg Endosc 2003;17:651-3.

32. American Geriatrics Society Ethics Committee and Clinical Practice and Models of Care Committee. American Geriatrics Society feeding tubes in advanced dementia position statement. J Am Geriatr Soc 2014;62:1590-3.

33. Australian and New Zealand Society for Geriatric Medicine. Position statement 12: Dysphagia and aspiration in older people. Available from http://www.anzsgm. org/documents/PS12DYSPHAGIA2010cleanfinal.pdf. Accessed 18 Mar 2017.

34. Hanson LC, Ersek M, Gilliam R, Carey TS. Oral feeding options for people with dementia: a systematic review. J Am Geriatr Soc 2011;59:463-72.

35. Luk JK, Chan FH, Hui E, Tse CY. The feeding paradox in advanced dementia: a local perspective. Hong Kong Med J 2017;23:306-10.

36. Working Group on Modular Review of HA Guidelines on Life-Sustaining Treatment. HA guidelines on life-sustaining treatment in the terminally ill. 2015. Available from: http:// www.ha.org.hk/haho/ho/psrm/HA_Guidelines_on_Life sustaining_treatement_en_2015.pdf. Accessed Aug 2017.

37. Hong TC, Lam TP, Chao DV. Barriers for primary care physicians in providing palliative care service in Hong Kong-qualitative study. Hong Kong Pract 2010;32:3-9.

38. White paper - Quality of Death Index 2015. Available from: http://www.eiu.com/industry/article/1413563125/ white-paper-quality-of-death-index-2015/2015-10-09. Accessed 18 Mar 2017.

39. The Law Reform Commission of Hong Kong. Enduring powers of attorney: personal care. Available from: http:// www.hkreform.gov.hk/en/docs/repa2_e.pdf. Accessed 29 Apr 2017. 